\title{
APONTAMENTOS INICIAIS- YARA GUASQUE: \\ Do Pictórico Ao Digital
}

\author{
Sandra Makowiecky ${ }^{1}$ \\ Luciana Marcelino ${ }^{2}$
}

\section{RESUMO}

Este artigo visa analisar e registrar a transição do pictórico ao digital no pensamento e na produção da artista Yara Guasque, professora do curso de Artes Visuais da Universidade do Estado de Santa Catarina, pesquisadora em arte e tecnologia. Seu percurso artístico e intelectual parte de uma produção pictórica nos anos 80 e 90, centrada em pinturas monocromáticas de grandes dimensões com aplicação de têmpera sobre lona, na qual encontramos questões formais como cor e dimensão, que a aproximam dos artistas expressionistas abstratos da década de 50, especialmente com Mark Rothko, artista de maior aproximação. Transfere-se para o campo das artes digitais a partir dos anos 2000, cujos trabalhos tornam-se ainda mais experimentais e colaborativos. Percurso sintomático da atual mudança de paradigmas analógico/digital, o artigo busca analisar os atravessamentos do conceito de imersão tanto na produção pictórica quanto na produção digital realizada pela artista. Partindo das possibilidades imersivas do campo pictórico chega-se ao estudo da imersão em telepresença nos trabalhos experimentais realizados pelos grupos Perforum Desterro e Perforum São Paulo, coordenados, respectivamente, por Yara Guasque e Artur Matuck.

Palavras Chave

Imersão, pictórico, expressionismo abstrato, arte virtual, telepresença.

\footnotetext{
${ }^{1}$ Orientadora, Professora do Departamento de Artes Visuais - CEART/UDESC, sandra.makowiecky@udesc.br

${ }^{2}$ Acadêmica do Curso de Licenciatura em Artes Visuais, CEART/UDESC, bolsista de iniciação científica PROBIC/CNPq.
} 


\begin{abstract}
This article aims to analyze and record the transition from pictorial to digital in thought and production of the artist Yara Guasque, Professor of Visual Arts at the University of the State of Santa Catarina and researcher in art and technology. Her artistic career and intellectual moves from a pictorial production in the $80 \mathrm{~s}$ and $90 \mathrm{~s}$, focused on large monochrome paintings by applying tempera on canvas, in which we find formal questions such as color and size, that approach her work of abstract expressionist artists of the decade 50, especially Mark Rothko, artist closer. Then she moved to the field of digital arts from the 2000s, whose works become even more experimental and collaborative. Her way is symptomatic of the current paradigm shift analog/digital, the article seeks to analyze the crossings of the concept of immersion in both pictorial and digital production performed by the artist. Starting from the immersive possibilities of pictorial field comes to the study of immersion in telepresence through experimental work carried out by groups Perforum Desterro and Perforum São Paulo, coordinated respectively by Yara Guasque and ArturMatuck.
\end{abstract}

Key words

Immersion, pictorial, abstract expressionism, art virtual, telepresence.

\title{
Introdução
}

A artista plástica Yara Guasque apresenta um percurso que parte da pintura e gravura nos anos 80 e 90 para chegar à relação da arte com a tecnologia, às novas mídias e às artes digitais a partir do início do novo milênio. Se considerarmos o advento da era digital como um momento de mudança de paradigmas, o percurso de Yara é sintomático deste processo. Este artigo pretende compreender o percurso realizado e os motivos que levaram a artista a abandonar uma pesquisa pictórica concebida em meios/suportes mais tradicionais como pintura, gravura, para se debruçar sobre o novo mundo das artes digitais.

Yara graduou-se em artes plásticas pela FAAP em 1979, desde então sua produção foi marcada pela gravura e pintura, especialmente a xilogravura e as 
pinturas com têmpera e aquarela. Em 1995, Yara realiza uma exposição individual no MASC intitulada "A questão da cor", onde a própria artista coloca que havia uma preocupação com a pesquisa cromática: "as pinturas tentam explicitar a natureza contrastante da cor"3.

Em relação a sua produção acadêmica, em 1998, Yara escreve sua dissertação de mestrado que consiste em uma análise literária sobre a obra de Goethe "Para uma Teoria das Cores". Ainda que não possamos encontrar nesta dissertação referência direta ao seu trabalho com pintura, podemos identificar relações indiretas como em uma série de trabalhos intitulados "O mar é roxo, verde são seus olhos azuis" que segundo a artista resultaram da sua pesquisa sobre a teoria das cores. Esta série produzida entre 1995 a 2001 compõem-se de pinturas de têmpera sobre lona, gravura, painel eletrônico e um site.

A transição do pictórico ao digital também se dá no interior do pensamento e da pesquisa acadêmica de Yara. Em 2003, ela escreve sua tese de doutorado denominada "Telepresença: interação e interfaces" e em 2007 uma série intimista de desenhos e aquarelas produzidos durante quase duas décadas são apresentadas em exposição retrospectiva no MASC sob o título de "Sou alma pequenina". Atualmente, Yara Guasque é professora efetiva do curso de artes visuais daUniversidade Estadual de Santa Catarina, onde desenvolve pesquisas em arte e tecnologia com o grupo Tecnofagia.

\subsection{Do Pictórico}

Para iniciar a abordagem teórica sobre o trabalho de Yara, vamos utilizar como ponto de partida metodológico o pensamento do teórico da arte Yves-Alain Bois $^{4}$, o qual sugere que o olhar sobre a obra entrevê os caminhos teóricos a serem percorridos. Na introdução do livro "A pintura como modelo", Bois faz uma crítica às diversas correntes teóricas que disputam entre si o lugar da teoria dominante. $\mathrm{O}$ autor parte da premissa de que não se deve aplicar uma teoria ao objeto de estudo, mas que a partir do objeto é que se encontra uma teoria aplicável. Com isto, ele

\footnotetext{
${ }^{3}$ Jornal A Notícia, Seção Variedades, terça-feira, 18 de abril de 1995, Joinville/SC.
}

${ }^{4}$ BOIS, Yve-Alain. A Pintura como Modelo. São Paulo, Martins Fontes. 2009. 
resgata em parte um formalismo teórico abandonado após Greenberg, ao mesmo tempo em que desvincula sua teoria da obrigação de uma interpretação sociopolítica estabelecida pela geração marxista.

Bois contrapõem dois modelos teóricos de história da arte que dominaram o século $X X$, mais acentuadamente no âmbito americano: o discurso formalista que se desenvolveu com o empreendimento de Greenberg nos anos 50 e 60 e a iconografia panofskiana. Todo esse debate, formalistas de um lado, iconologistas de outro, é tido por Bois como um sintoma daquilo que é chamado por Barthes de assimbolismo a incapacidade de perceber a infinita proliferação semântica que forma o tecido da obra de $a^{2} e^{5}$. Como se estivéssemos discutindo quantos anjos dançam na cabeça de um alfinete, conforme Wolfe $(1987)^{6}$.

Para Bois, as correntes teóricas como a sócio-política, a psicocrítica, o antiformalismo, a iconologia, entre outras, recusam examinar a obra em sua especificidade, tratando-a como um documento, ao invés de monumento. O autor propõe como reação ao que ele chama de assimbolismo generalizado, o resgate do formalismo baseado na retórica russa, onde ele evoca neste formalismo uma missão essencial precisamente a definição de mediações entre o espaço semântico da obra, suas estratégias formais e tudo o que ela não é [o mundo, a história, a luta de classes, a biografia, a tradição, todo o resto] $]^{7}$.

\subsection{Pintura Plana}

Segundo o escritor e jornalista Tom Wolfe, no período do pós-guerra, quando o ponto central da arte se desloca de Paris a Nova York, surge com força no cenário artístico norte-americano o movimento conhecido por expressionismo abstrato e a teoria da pintura plana de Clement Greenberg. A teoria da pintura plana retorna aos cubistas e outros modernistas, que recusaram os efeitos ilusórios da profundidade no plano, para exemplificar uma espécie de avanço teórico da arte moderna, no sentido de alcançar a pureza da pintura pela sua planitude. Ainda que os cubistas e os modernistas "primitivos" tentassem eliminar a terceira dimensão da pintura ao

\footnotetext{
BARTHES R. apud BOIS, Yve-Alain. A Pintura como Modelo. São Paulo, Martins Fontes. 2009. P. xxiv. WOLFE, Tom. A palavra pintada. Porto Alegre: LPM, 1987.

BOIS, Yve-Alain. Viva o formalismo (bis), 1989. In: COTRIM, Cecília e FERREIRA, Glória. Clement Greenberg e

o debate crítico. Rio de janeiro, Zahar, 2001. P. 248
} 
fugirem da figuração e do naturalismo, estes primeiros artistas abstratos mantiveram linhas, formas, contornos e cores.

Em seu ensaio "Pintura Modernista" de 1960, Greenberg entrega a tridimensionalidade ao domínio da escultura e considera que a pureza da pintura e a preservação de sua autonomia deveria se dar através do abandono de tudo que se pudesse compartilhar com a escultura. Assim, a arte abstrata excluiu o representativo e o literário do campo de atuação, enfatizando o quadro plano. Greenberg propunha então a integridade do plano do quadro como hipótese artística para a arte moderna. Inicia-se assim uma obsessão, na opinião de Tom Wolfe, pela integridade do plano entre os pintores abstratos nova-iorquinos, tendo comosuporte e sustentação a teoria Greenberginiana. Sendo o expressionismo abstrato a abstração da própria abstração que foi o cubismo, a teoria torna-se combustível para a produção artística apoiando-a, reforçando-a e promovendo-a. Para Wolfe, a necessidade de uma teoria que sustente a produção artística irá seguir até o surgimento da arte conceitual.

\subsection{Mark Rothko e a abstração imersiva - a vertente norte-americana.}

É neste cenário teórico que Mark Rothko, judeu russo radicado nos EUA, aparece como um dos grandes expoentes da pintura expressionista abstrata americana. No início de sua carreira, em meados da década de 20, Rothko ainda pintava uma figuração de bases no expressionismo alemão. A abstração pictórica que conhecemos como característica de Rothko surge como produto de um processo intenso de meditação e pensamento pelo qual o artista passou. Processo esse vinculado a uma busca de precisão na solução deuma questão pictórica específica, centrada na cor, mas que também revela dentro dessa busca quase matemática um forte aspecto transcendente. Nesse sentido, pode-se especular asinfluências de Rothko advindas da pintura suprematista de Malevich. Segundo Simon Shaman, ao contemplar uma pintura de Matisse, Rothko se dá conta de como a cor extravasa as formas impostas pela linha, inundando o quadro de vibrações vermelhas.

\footnotetext{
${ }^{8}$ GREENBERG, C. Pintura Modernista, 1960. In: COTRIM, Cecília e FERREIRA, Glória. Clement Greenberg e o debate crítico. Rio de janeiro, Zahar, 2001.
} 
Rothko é o único que parece estar ligado a alguma área da arte francesa após o impressionismo, e sua habilidade em sugerir contrastes de valor e calor em oposições de cor pura me fazem pensar em Matisse, que investiu nos contrastes de valor mais ou menos da mesma maneira ${ }^{9}$.

As variadas influências de Rothko destacadas acima convergem para uma questão que considero primordial na sua produção: a pesquisa cromática imersiva. O que desejo destacar na obra de Rothko é o aspecto imersivo das suas pinturas abstratas. A transcendentalidade quase religiosa que atribuíram a ele diz respeito à imersão subjetiva pictórica produzida no fruidor; um perder-se entre as cores, que despertam conteúdos emocionais primários como: tranquilidade, medo, insegurança, força e êxtase. Essas possibilidades sensórias emergem conforme a vibração do campo de cor nas pinturas $^{10}$. Assim, enquanto Greenberg destaca uma busca pela pureza formal na análise das pinturas expressionistas abstratas ${ }^{11}$, Rothko busca as propriedades subjetivas das cores, que se tornam indissociáveis da fruição de suas telas no sentido das sensações proporcionadas. Elas abarcam o fruidor numa expansão espacial da cor para além dos limites bidimensionais da superfície pictórica, o que abre para outras dimensões de aspectos subjetivos.

\subsection{Lucio Fontana e a imersão em conceitos espaciais - vertente europeia.}

Também na Europa havia entre os artistas a necessidade de reformulações no campo da arte em decorrência dos desdobramentos da modernidade. No caso europeu, essas reformulações aparecem com maior ênfase no debate filosófico a respeito da sensibilidade do espectador em relação ao tempo, espaço e matéria; reagindo contra o caráter físico e instintivo do estilo informal, equivalente europeu do

\footnotetext{
${ }^{9}$ GREENBERG, C. Pintura à Americana, 1960. In: COTRIM, Cecília e FERREIRA, Glória. Clement Greenberg e o debate crítico. Rio de janeiro, Zahar, 2001. P.89.

${ }^{10}$ Campo de cor ou colourfieldpainting refere-se a um termo utilizado essencialmente para referência a alguns artistas expressionistas abstratos da década de 1950 para os diferenciar dos Actionpainters (como Kooning, Klein, Pollock). Os colour-fieldpainters (como Gottlieb, Motherwell, Newman, Reinhardt, Rothko) preocupavam-se com a imagem abstrata que era constituída por uma forma ou área grande de cor unificada.

11 WOLFE, Tom. A palavra pintada. Porto Alegre: LPM, 1987.
} 
Expressionismo abstrato $^{12}$. Uma contraposição crítica da teoria pintura plana proposta por Greenberg pode ser vista, por exemplo, nas obras do neo-realismo europeu, como a do italiano Lucio Fontana. Ele foi um destes artistas que ao retalhar ou golpear suas telas, exerceu um rompimento com a bidimensionalidade da pintura para criar um espaço além dela, como em seu projeto intitulado Conceitos Espaciais produzido na década de 50. Tratam-se de pinturas em sua maioria monocromáticas que são golpeadas de modo a ampliarem a superfície da pintura para além de sua bidimensionalidade, o que Fontana entendiapelo termo "espacialismo"13.

No "espacialismo" a pintura ganha espaço para além da bidimensionalidade, assim ela abarca uma potência imersiva para o fruidor não mais pelo campo de cor, mas pelafissura ou rasgo do próprio espaço da obra que passa transbordar dos seus limites internos. Assim, se em Rothko os limites da pintura são extrapolados pelas intensidades vibratórias dos campos cromáticos em uma escala que abarca o fruidor, em Fontana os limites são extrapolados nos rasgos internos à tela, conferindo à pintura uma tridimensionalidade que joga entre as fronteiras pictóricas e escultóricas. Nesse sentido, lemos duas possibilidades imersivas dadas pela cor em grandes formatos e pelo rasgo das telas.

\subsection{Yara Guasque e a imersão pictórica}

Yara Guasque, a nosso ver, transita entre a vertente norte americana e a vertente europeia. Com relação a vertente norte - americana, em 1995, Yara realiza uma exposição individual no Museu de Arte de Santa Catarina contendo uma série de pinturas de têmpera sobre lona de grandes dimensões, entre outros trabalhos. A exposição intitulava-se "A questão da cor" e segundo a artista, as pinturas daquela exposição tentavam explicitar a natureza contrastante da cor. Com estas características, o seu trabalho levanta questões relativas ao color fieldpaintings do expressionismo abstrato norte- americano, o que a aproxima de Mark Rothko.

Para análise da produção pictórica de Yara Guasque escolheu-se três obras significativas produzidas na década de 90, presentes nesta exposição. São pinturas com aplicações em veladura de têmpera sobre lona, cujos efeitos criam campos de cor atmosféricos. Nas pinturas intituladas $O$ Incerto, Rubens e Yarapodemos

\footnotetext{
${ }^{12}$ READ, Herbert. História da pintura moderna. São Paulo: Círculo do Livro, 1974.

13 Idem, Ibidem.
} 
perceber algumas características formais semelhantes: formato quadrangular das telas em grandes dimensões com 1,98 m por 1,98 m; sobreposições suaves de camadas de cor baseadas em tons pastéis oscilando entre os campos cromáticos de amarelo e azul; além de traçados brancos na vertical que criam uma densidade etérea sobre o plano pictórico, uma luminosidade efusiva. Todas essas características funcionam como atrativos que, a partir da sensação, descortinam uma condição imersiva para o fruidor.

Com relação à vertente europeia, vemos outras possibilidades de aproximação. Nas pinturas Sem Título de 1994 e 1995, Yara Guasque opera em suas composições com as duas possibilidades de imersão: a cor e o rasgo nas telas. Essas pinturas mantêm os grandes formatos com a investigação de campos cromáticos como nas telas descritas acima e agrega outro elemento compositivo, os cortes ovalados nas lonas que são sobrepostas a outras. Na pintura Sem Título de 1995, a camada de fundo de lona possui uma cor única e chapada em tom ocre que contrasta com as cores mais dinâmicas e vibráteis da camada superior com tonalidades azuladas. Já na pintura da Sem Título de 1994, o que vemos é uma complexidade da composição no sentido do uso das duas estruturas imersivas. Nela o plano de fundo é composto por cores vibráteis avermelhadas com rajadas que dinamizam e lançam a cor para fora da superfície bidimensional que, por sua vez, ocorre uma sobreposição com lona de cor azul chapado e com rasgos ovais permitindo que emerjam as cores do plano de fundo. Esses cortes também possuem no plano de fundo uma espécie de negativo, dado em espaços ovais de dimensões similares aos cortados e pintados em tons de branco. Assim as pinturas ganham através dos cortes uma outra possibilidade dimensional, semelhante àquelas que do "espacialismo" de Fontana.

Nesta trajetória brevemente delineada podemos ler nos trabalhos de Yara uma afirmação do aspecto imersivo da pintura dada tanto pelo campo cromático como pela cisão da bidimensionalidade da tela. Se por um lado a imersão ocorre de forma expandida pela vibração do campo cromático, por outro trata-se de uma imersão sintética dada pela fissura da noção tradicional do plano da pintura. Lançamos como hipótese que esse aspecto imersivo em sua obra pode ser a base para uma leitura que faz a passagem do pictórico para o digital em sua produção recente, na medida em que o digital reafirma as possibilidades imersivas em outras materialidades a partir das mídias virtuais que funciona também como campo 
expressivo.

\section{Referências Bibliográficas}

BENJAMIN, Walter. Trauerspiel and tragedy.In: Selected writings (vol.1).Cambridge (Mass.).: Belknap Press, 2004.

BOIS, Yve-Alain. A Pintura como Modelo. São Paulo, Martins Fontes. 2009.

COTRIM, Cecília e FERREIRA, Glória. Clement Greenberg e o debate crítico. Rio de janeiro, Zahar, 2001.

GRAU, Oliver. Arte Virtual: da ilusão à imersão. Editora UNESP, Editora Sesc. São Paulo, 2007.

Guasque, Yara; Araujo, Yara R. G. Elementos estruturais de 'Para uma teoria das cores' de Goethe. Florianópolis, 1998. 99 f. Dissertação (Mestrado), Universidade Federal de Santa Catarina, 1998.

GUASQUE, Yara; Araujo, Yara R. G.Telepresença: interação e interfaces. Editora PUC, São Paulo, 2003.

GUASQUE, Yara; Araujo, Yara R. G..Perforum Desterro e Perforum São Paulo: repensando a colaboração entre a periferia e os centros. Disponível em: <http://webartes.dominiotemporario.com/performancecorpopolitica/textes\%20pdf/yar a\%20perforum\%20desterro.pdf>. Acesso: 04 jul. 2013.

GUASQUE, Yara; Araujo, Yara R. G. (Tele)+Presença e VR. Disponível em:<http://www.compos.org.br/data/biblioteca_914.pdf>. Acesso em: 15 jun. 2013.

READ, Herbert. História da pintura moderna. São Paulo: Círculo do Livro, 1974.

WOLFE, Tom. A palavra pintada. Porto Alegre: LPM, 1987. 